\title{
ZOMBIES, EPIPHENOMENALISM, AND PERSONAL EXPLANATIONS: A TENSION IN MORELAND'S ARGUMENT FROM CONSCIOUSNESS
}

\author{
DANIEL LIM
}

University of Cambridge

\begin{abstract}
In his so-called Argument from Consciousness (AC), J.P. Moreland argues that the phenomenon of consciousness furnishes us with evidence for the existence of God. In defending AC, however, Moreland makes claims that generate an undesirable tension. This tension can be posed as a dilemma based on the contingency of the correlation between mental and physical states. The correlation of mental and physical states is either contingent or necessary. If the correlation is contingent then epiphenomenalism is true. If the correlation is necessary then a theistic explanation for the correlation is forfeit. Both are unwelcome results for AC.
\end{abstract}

\section{INTRODUCTION}

Recently J.P. Moreland (1998, 2003, 2008) has argued that non-physical mental states - their existence and correlation with physical states provide evidence for the existence of God. He regiments his argument as follows:

1. Genuinely nonphysical mental states exist.

2. There is an explanation for the existence of mental states.

3. Personal explanation is different from natural scientific explanation.

4. The explanation for the existence of mental states is either personal or natural scientific.

5. The explanation is not natural scientific.

6. Therefore the explanation is personal.

7. If the explanation is personal then it is theistic.

8. Therefore the explanation is theistic. 
The so-called Argument from Consciousness (AC) is essentially a Godof-the-gaps argument. That is, a putative gap in our scientific knowledge regarding nonphysical mental states is taken to be evidence for the existence of God.

$\mathrm{AC}$ rests on a number of contentious premises. Premise (1) is at the heart of several heated debates in contemporary philosophy of mind. Many working in this area of philosophy are physicalists ${ }^{1}$ and they reject (1). Moreland, though he offers a set of 'standard' reasons in support of (1), states up front that he does not intend to give a rigorous defense. Instead he assumes the truth of (1) 'for the sake of argument.' This is not an insignificant point because it clearly demarcates the target audience of AC - naturalists who countenance nonphysical mental states. ${ }^{2}$ I will refer to the members of this target audience as naturalistic dualists. Moreland's hope is that $\mathrm{AC}$ will persuade naturalistic dualists to become theists.

Another contentious premise is (5). Moreland offers four reasons in defense of this premise: (a) the uniformity of nature, (b) the contingency of the mind-body correlation, (c) the rejection of epiphenomenalism based on causal closure, and (d) the inadequacy of evolutionary explanations. Though there are important things to be said regarding each of these reasons, careful reflection on reasons (b) and (c) in particular gives rise to an unpalatable tension in Moreland's defense of AC. The remainder of this paper will be devoted to developing this tension into a dilemma.

\section{REASON (B): RADICAL CONTINGENCY}

One reason there is no natural scientific explanation for mental states, Moreland argues, is because the correlation between mental states and physical states is 'radically contingent'. This reason is really composed of two parts: an epistemological part involving the term 'radical' and a metaphysical part involving the term 'contingent'. To begin, consider what Moreland means when he says that the mental-physical correlation is radically contingent. He writes:

\footnotetext{
${ }^{1}$ Some notable contemporary physicalists are Jaegwon Kim $(2000,2005)$ and David Papineau (2002).

${ }^{2}$ A notable contemporary naturalistic dualist is David Chalmers $(1996,2010)$.
} 
Why do pains instead of itches, thoughts or feelings of love get correlated with specific brain states? No amount of knowledge of the brain state will help to answer this question. For the naturalist, the regularity of mindbody correlations must be taken as contingent brute facts. (Moreland 2003, p. 208, my emphasis)

Moreland is making an epistemological claim. Because the mentalphysical correlation is radically contingent 'no amount of knowledge' of the brain can explain why certain mental states are correlated with certain brain states. All that can be said, as committed naturalists, is that this brain state is correlated with that mental state - end of story. As such there is no natural scientific explanation forthcoming. In the absence of an explanation, naturalistic dualists are left to baldly announce that the correlations are brute facts of nature.

To simply assert that the correlations are brute facts of nature, however, begs the question against theistic dualists like Moreland who claim to have an explanation for the correlations. This is where the second part of reason (b) comes into play. The correlation between mental and physical states is radically contingent. To say that the correlation is contingent is to make a metaphysical claim. It is to claim that there are possible worlds where mental and physical states come apart in various ways. Let's call this claim Contingency. Moreland describes some of these possible worlds as follows:

For example, given a specific brain state normally 'associated' with the mental state of being appeared to redly, inverted qualia worlds (worlds with that physical state but radically different mental states 'associated' with it), zombie worlds (worlds with that physical state and no mental states at all), and disembodied worlds (worlds with beings possessing mental states with no physical entities at all) are still metaphysically possible.

(Moreland 2003, p. 213)

Asserting Contingency, therefore, commits one, among other things, to the possibility of inverted qualia worlds, zombie worlds, and disembodied worlds.

Contingency is critical to reason (b) because it makes room for a personal explanation of the correlation between mental and physical states. In effect it provides a foundation on which premise (6) of AC can be grounded. Moreland writes: 
... the fact that the existence of consciousness and its precise correlation with matter is contingent fits well with a theistic personal explanation that takes God's creative action to have been a contingent one. God may be a necessary being, but God's choice to create conscious beings and to correlate certain types of mental states with certain types of physical states were contingent choices, and this fits nicely with the phenomena themselves. (Moreland 2003, p. 208, my emphasis)

Not only does Contingency 'fit well' with a personal explanation it seems that Contingency is required for a personal explanation. This is because offering a theistic personal explanation of a given phenomenon seems to presuppose the contingency of the phenomenon to be explained. This is especially so given Moreland's construal of God as an agent with libertarian freedom. He writes, "God is free to act or refrain from acting in various ways." That is, the explanandum of a theistic personal explanation must be contingent since it depends on God's free choice. There must be some possible worlds that give content to the claim that God chose to render the relevant phenomenon in a certain way and other possible worlds that give content to the claim that God chose not to render the relevant phenomenon in a certain way. For consider what it would be like to offer a theistic personal explanation for the mind-body correlation if the correlation were necessary. That is, what if there were no possible worlds where the relevant mental and physical states come apart? What, then, would the prospects be for offering a personal explanation of the correlation in terms of God's choice when there are no possible worlds to make sense of God's ability to do otherwise? The prospects do not seem promising.

Perhaps the same point can be made more clearly by borrowing an image from Kripke (1972). Suppose we imagine God creating the world. What does God need to do after he creates everything physical in the world? If Contingency is true it seems God is now faced with a myriad of choices. God must decide which mental states to correlate with the various brain states that have already been created. He must decide whether or not to correlate an itch with this brain state, a pain with that brain state, and so on. Because, according to Contingency, there are no necessary connections between mental and physical states it is easy to see why a theistic personal explanation for the correlations 'fits well' with the 
phenomena. But imagine what it would be like if the correlation between mental and physical states were necessary. When God finishes creating everything physical he would have nothing left to do regarding the mental since there is a necessary correlation between mental and physical states. God's creating the physical would automatically bring the mental into existence as well. Rejecting Contingency, therefore, would seriously undermine the plausibility of offering a theistic personal explanation for the mental-physical correlation.

The upshot is that Contingency is critical for the success of AC. A theistic personal explanation for the mind-body correlation requires Contingency. Without this Moreland's argument falters in its main objective - convincing others that a theistic personal explanation of the mind-body correlation is preferable over a natural scientific explanation.

\section{REASON (C): THE FALSITY OF EPIPHENOMENALISM}

Another reason there is no natural scientific explanation for mental states, Moreland argues, is because naturalism, at least the dualist varieties, is false. Naturalistic dualism is false because: naturalists are committed to Closure (the causal closure of the physical domain), Closure entails epiphenomenalism, and epiphenomenalism is false. Moreland writes:

... epiphenomenalism is false. Mental causation seems undeniable... [as

such] the admission of epiphenomenal nonphysical mental entities may

be taken as a refutation of naturalism. (Moreland 2003, p. 209)

The idea is straightforward. If a theory entails epiphenomenalism then that theory is false and any false theory is precluded from providing legitimate explanations. It follows that naturalistic dualism is false since naturalistic dualism entails epiphenomenalism. Consequently there can be no natural scientific explanations that are derived from naturalistic dualism.

Let me take things a bit slower. Closure is the claim that physical events only have physical causes. Moreland describes Closure as follows:

... when one is tracing the causal antecedents of any physical event, one will never have to leave the level of the physical. Physical effects have only physical causes... (Moreland 2003, p. 209) 
Closure eliminates the possibility of nonphysical entities having causal effects in the physical world. This poses a serious problem for naturalistic dualists. Because naturalistic dualists are committed to naturalism they are obliged to accept Closure, or so Moreland claims. Because naturalistic dualists are also committed to the nonphysical nature of mental states according to premise (1) of AC, naturalistic dualists are obliged, in light of Closure, to accept epiphenomenalism. Consequently naturalistic dualists must also accept epiphenomenalism. But if epiphenomenalism is false, as Moreland rightly asserts, it follows that naturalistic dualism must be false. As a result the possibility of securing a natural scientific explanation for mental states within the framework of naturalistic dualism is forfeited.

The claim that Closure entails epiphenomenalism, I realize, is controversial. ${ }^{3}$ My purpose in rehearsing Moreland's logic is not to get embroiled in the debates over mental causation. It is simply to highlight Moreland's insistence on this entailment along with his insistence that epiphenomenalism is false.

Assuming Explanation refers to the claim that there is a theistic personal explanation for the mind-body correlation, the critical elements of my discussion of AC thus far can be summarized with the following three claims:

C1: Explanation $\rightarrow$ Contingency

C2: Naturalistic Dualism $\rightarrow$ Epiphenomenalism

C3: Epiphenomenalism

$\mathrm{C} 1$, captured as a conditional, is the claim that a theistic personal explanation of the mind-body correlation requires the contingency of the mental-physical correlation. C2, also captured as a conditional, is the claim that naturalistic dualism, given its commitment to Closure, entails epiphenomenalism. C3 is simply the rejection of epiphenomenalism.

\section{ZOMBIES AND EPIPHENOMENALISM: A DILEMMA}

There is, however, a tension in Moreland's development and defense of AC. His rejection of epiphenomenalism is at odds with his commitment

\footnotetext{
${ }^{3}$ Many contemporary non-reductive physicalists committed to Closure argue that mental states, despite being irreducible with respect to fundamental physical states, are causally efficacious. For interesting discussions on this see Kim $(2000,2005)$, Crisp \& Warfield (2001), and Bennett (2003).
} 
to Contingency because Contingency, as I will argue, actually entails epiphenomenalism. This claim can be captured as a further conditional.

C4: Contingency $\rightarrow$ Epiphenomenalism

To see why $\mathrm{C} 4$ is true consider the 'standard' way of characterizing zombies. ${ }^{4}$ A zombie is someone or something physically identical to me (or any other conscious being), but lacking conscious experiences altogether. My zombie twin is molecule-for-molecule identical to me (down to the low-level properties of physics) but without conscious experiences. If we assume that my zombie twin is also embedded in a physically identical world he will be identical to me functionally and behaviorally. If I yell 'ouch' from a burned finger my zombie-twin will also yell 'ouch'. Whatever I do my zombie twin will also do. My zombie twin and I are indistinguishable in terms of our behavior and physical structure down to the final detail.

According to Contingency zombie worlds like the one just described are possible. What does the possibility of a zombie world imply about the causal efficacy of mental states? Consider a possible world $P W_{\mathrm{z}} . P W_{\mathrm{z}}$ is a zombie world. As such $P W_{Z}$ is physically identical to $P W_{\Theta^{\circ}}$, the actual world, in every minute physical detail. Every physical event that occurs in $P W_{\circledast}$ also occurs in $P W_{\mathrm{Z}}$. The only difference between $P W_{\mathrm{Z}}$ and $P W_{\circledast}$ is that there are no mental states in $P W_{Z}$. Since there are no mental states in $P W_{\mathrm{Z}}$ it follows that every physical event in $P W_{\mathrm{Z}}$ will have a causal explanation that is independent of any mental state. Take for instance the physical event, call it $E$, of my yelling 'ouch' after getting burned. E occurs in both $P W_{\Theta}$ and $P W_{\mathrm{Z}}$. What is the cause of $E$ in $P W_{\mathrm{Z}}$ ? Presumably it is some physical brain state, call it $P$, in my zombie twin. $P$ causes $E$ in $P W_{\mathrm{z}}$. What does this tell us of the relevant causal relations in $P W_{\circledast}$ ? In $P W_{\circledast}$ I am also in physical brain state $P$ and I also yell 'ouch'. That is, both $P$ and $E$ occur in $P W_{\Theta^{\circ}}$. The critical difference is that I am also in mental state $M$ in $P W_{\Theta}$. But what is the causal status of $M$ with regard to $E$ ?

Here it seems we have a situation that is ripe for applying Mill's Difference Method $^{5}$ (or something like it). Let's assume we can control all the relevant variables when running two experiments, one with potential causal factors $A$ and $B$ and another experiment, ceteris paribus, with only

\footnotetext{
${ }^{4}$ For more on zombies see Chalmers (1996, 2010).

${ }^{5}$ For a good discussion of Mill's Difference Method see chapter 2 of Psillos (2002).
} 
$A$. Both experiments yield effect $C$. Given these results it seems we can safely conclude that $B$ is causally irrelevant, or epiphenomenal, with regard to $C$. Since $C$ continues to occur, ceteris paribus, even in the absence of $B$ we know that $B$ cannot be a cause of $C$. In the same way, returning to the mental-physical case, since $E$ continues to occur, ceteris paribus, even in the absence of $M$ in $P W_{\mathrm{Z}}$ we know that Es occurring in $P W_{\circledast}$ has nothing to do with $M$ either. This shows that Contingency, because it entails the possibility of zombie worlds, leads to epiphenomenalism.

Moreland is now faced with an uneasy tension. According to $\mathrm{C} 1$ Moreland must be committed to Contingency in order to make a theistic personal explanation for the mental-physical correlation possible. According to $\mathrm{C} 4$, however, a commitment to Contingency leads to epiphenomenalism. But Moreland, according to C3, rightly rejects epiphenomenalism. A dilemma can now be formulated.

9. Moreland must accept or reject Contingency.

10. If he accepts Contingency then he must also accept Epiphenomenalism.

11. If he rejects Contingency then he must also reject Explanation. Contingency must either be accepted or rejected. If Contingency is accepted proponents of $\mathrm{AC}$ are forced to accept epiphenomenalism. If Contingency is rejected proponents of ACare forced to forfeit Explanation. Essentially Moreland is left with two choices: accept epiphenomenalism or forfeit Explanation. Both options are undesirable.

\section{AN OBJECTION}

One way of avoiding the dilemma is to reject C4: Contingency $\rightarrow$ Epiphenomenalism. Just because zombie worlds demonstrate that everything physical in $P W_{z}$ can go on just as it does in $P W_{\Theta}$ in the absence of mental states it does not follow that mental states are epiphenomenal. Isn't it possible for mental states to be causally efficacious in $P W_{@}$ and still have everything physical in $P W_{\mathrm{z}}$ go on just as it does in $P W_{\Theta}$ in the absence of mental states so long as $P W_{\mathrm{z}}$ is a counter-nomological world? That is, so long as the laws of nature in $P W_{\mathrm{Z}}$ differ from the laws of nature in $P W_{\Theta}$ ?

Let's assume that mental states are casually efficacious in the actual world. It is the conjunction of my mental state and my brain state that 
bring about my yelling 'ouch'. That is, $M$ and $P$ together cause $E$ in $P W_{\circledast}$ : $M \& P \rightarrow E$. If, however, $M$ makes a causal difference regarding $E$ in $P W_{@}$ then, ceteris paribus, it seems $E$ should not obtain in $P W_{\mathrm{z}}$ since $M$ is absent. But one might argue that $E$ can still obtain in the absence of $M$ if we consider a different possible zombie world $P W_{Z \text {-LAW }}$. In $P W_{Z \text {-LAW }}$, unlike $P W_{Z}$, the laws of nature differ from the laws of nature in $P W_{\Theta^{\circ}}$. $P W_{Z \text {-LAW }}$ is a counter-nomological world. Perhaps there is a law of nature in $P W_{\circledast}$ that ensures $E$ is brought about only by the conjunction of $M$ and $P$. In $P W_{Z-L A W}$, however, there is a different law of nature - one that ensures $P$ brings about $E$, even in the absence of $M: P \rightarrow E$. So we have a possible world, namely $P W_{Z \text {-LAW }}$, that seems to demonstrate the falsity of Contingency $\rightarrow$ Epiphenomenalism.

There are at least two things to be said in response to this. First, it is unclear whether or not we can say that the identity of physical brain state $P$ is preserved when considering $P$ in both $P W_{@}$ and $P W_{\text {Z-LAW }}$. More generally, it is unclear whether physical identity is preserved across counter-nomological worlds. ${ }^{6}$ Take, for example, the proton. Protons have a certain causal profile in the actual world. It is possible, however, for protons to take on different causal profiles in counter-nomological worlds. Perhaps protons could take on the causal profile of an actual world electron and still maintain their identity as protons. But this very possibility - the possibility that a proton could behave exactly like an electron, yet remain a proton - is bizarre by my lights.

Furthermore this position leads to an unparsimonious proliferation of possibilities. For every possible world we had once entertained we would have to include a vast number (perhaps an infinite number) of new possibilities. We would be forced to countenance a new possibility for each possible assignment of causal profiles to the various physical entities. All such possible worlds will be indistinguishable with respect to each other. That is, they will be empirically equivalent worlds. The laws of nature in these worlds will be indistinguishable and all the experiments that work in the actual world will proceed in exactly the same way in these

${ }^{6}$ For more on this debate see Bird $(2005,2007)$ and Ellis (2001). Bird poses the question in terms of essential or contingent causal profiles. Those who claim that causal profiles are contingent he calls Categoricalists and those who claim that causal profiles are essential he calls Dispositional Essentialists. Ellis provides compelling reasons to reject categoricalism. 
worlds. Nevertheless these worlds will be different from the actual world (and different from each other) because the physical entities have all been mixed and matched with different causal profiles. These differences will have nothing to do with how we investigate, confirm, or even express the laws of nature that govern these worlds, but they will still be different because the physical entities that serve as the relata in these laws will be different.

So it seems there is good reason to think physical identity is not preserved across counter-nomological worlds. To see why this matters regarding C4 consider, again, what Contingency amounts to. It is the claim that the correlation between mental and physical states is contingent. In order for Contingency to remain a meaningful claim the very same mental states and physical states must come apart in certain possible worlds. But when we consider counter-nomological worlds it is not obvious whether or not the identity of physical states are preserved. Indeed there is good reason to believe that $P$, the relevant physical brain state, does not even exist in $P W_{\mathrm{Z} \text {-LAW }}$ But if the identity of $P$ is not preserved across counter-nomological worlds then it seems $P W_{\mathrm{Z} \text {-LAW }}$ cannot be used to undermine $\mathrm{C} 4$.

Second, $P W_{\text {Z-LAW }}$ is a red herring. Even if physical identity were preserved across counter-nomological worlds the possibility of $P W_{\text {Z-LAW }}$ does not have any real bearing on the truth or falsity of Epiphenomenalism so long as $P W_{\mathrm{z}}$ remains possible. And it is the possibility of $P W_{\mathrm{Z}}$, a possible world that is identical to $P W_{\Theta}$ in every way (including the laws of nature) minus the existence of mental states, that establishes epiphenomenalism. In other words, the possibility of $P W_{\mathrm{Z} \text {-LAW }}$ is orthogonal to the central issue. What really matters, regarding the truth or falsity of epiphenomenalism is the possibility of $P W_{\mathrm{z}}\left(\right.$ not $\left.P W_{\text {Z-LAW }}\right)$.

Perhaps, in response, one can simply dig in her heels and assert that zombie worlds like $P W_{\mathrm{z}}$ are impossible, or at least argue that zombie worlds are erroneously described since mental states are causally efficacious in $P W_{\Theta^{\circ}}$. Worlds like $P W_{\mathrm{Z}}$, contrary to the way they are 'standardly' described, cannot be identical with $P W_{\circledast}$ in all the physical events that occur in them. There will be events that occur in $P W_{\Theta}$ that do not occur in $P W_{\mathrm{Z}}$ (and vice versa) due to the presence (or absence) of mental states that make a causal difference in the kinds of physical events that occur. Zombies simply cannot be behaviorally identical with their conscious 
counterparts if we assume that mental states make a causal difference in $P W_{\Theta}$. For example, I might yell 'ouch' in $P W_{\Theta}$ because I am in mental state $M$. That is, $M$ is a casual factor in my yelling 'ouch'. My zombie twin in $P W_{\mathrm{Z}}$, however, will not yell 'ouch' since one of the necessary causal factors for my yelling 'ouch', namely $M$, is not present in $P W_{z}$.

There is no doubt that this move will preserve Contingency and undermine $\mathrm{C} 4$ but it does so at a price. In order to pursue this strategy one would be forced to reject Closure. We must remember that the casual efficacy of nonphysical mental states is a straightforward violation of Closure since Closure is the claim that physical events only have physical causes. Rejecting Closure, however, would be dialectically disastrous for proponents of AC. If you recall AC was formulated with naturalistic dualists in mind. The central purpose of the argument is to persuade naturalistic dualists to become theists. Rejecting Closure, however, is a move, at least according to Moreland, that is unavailable to naturalistic dualists since naturalists (in general) are committed to Closure. He writes, "Most naturalists believe that their worldview requires that all entities whatever are either physical or depend on the physical for their existence and behavior. One implication of this belief is commitment to [Closure]." Given this naturalist commitment it would be dialectically useless to undermine $\mathrm{C} 4$ by rejecting Closure.

\section{CONCLUSION}

There is a tension in AC that can be formulated as a dilemma against Moreland based on the acceptance or rejection of Contingency. One is forced either to accept epiphenomenalism or reject the possibility of a theistic personal explanation for mental states. Both options are undesirable. It seems, therefore, that $\mathrm{AC}$ in its present form cannot be used effectively to persuade naturalistic dualists to become theists. Perhaps AC can be appropriately revised. This, however, has yet to be seen.

\section{BIBLIOGRAPHY}

Bennett, Karen. 2003. "Why the Exclusion Problem Seems Intractable and How, Just Maybe, to Tract It." Nous 37, pp. 471-497.

Bird, Alexander. 2005. "Laws and Essences." Ratio 18, pp. 437-461. 
Bird, Alexander. 2007. Nature's Metaphysics: Laws and Properties. Oxford: Oxford University Press.

Chalmers, David. 1996. The Conscious Mind. Oxford: Oxford University Press.

Chalmers, David. 2010. The Character of Consciousness. Oxford: Oxford University Press.

Crisp, Thomas and Warfield, Ted. 2001. "Kim's Master Argument." Nous 35, pp. 304-316.

Ellis, Brian. 2001. Scientific Essentialism. Cambridge: Cambridge University Press.

Kim, Jaegwon. 2000. Mind in a Physical World: An Essay on the Mind-Body Problem and Mental Causation. Cambridge: MIT Press.

Kim, Jaegwon. 2005. Physicalism or Something Near Enough. Princeton, Princeton University Press.

Kripke, Saul. 1972. Naming and Necessity. Cambridge, Mass.: Harvard University Press.

Moreland, J.P. 1998. "Searle's Biological Naturalism and the Argument from Consciousness." Faith and Philosophy 15, pp. 68-90.

Moreland, J.P. 2003. “The Argument from Consciousness." In Paul Copan and Paul Moser (eds.) The Rationality of Theism. New York: Routledge, pp. 204-220.

Moreland, J.P. 2008. Consciousness and the Existence of God: A Theistic Argument. New York: Routledge.

Papineau, David. 2002. Thinking About Consciousness. Oxford: Oxford University Press.

Psillos, Stathis. 2002. Causation and Explanation. Ithaca: McGill-Queen's University Press. 